\title{
LAS ARMAS CON POMO EN FORMA DE ANILLO \\ Aportación al estudio de su evolución
}

\author{
POR \\ JUAN-EDUARDO CIRLOT
}

EL interés por este tipo de armas (espadas, dagas, puñales, cuchillos y sus formas intermedias o híbridas) proviene de una daga que llegó a mi poder, hace ya muchos años, procedente del mercado internacional de antigüedades. Es toda de una sola pieza y mide, en total, 42 centímetros, que se distribuyen del modo siguiente: hoja, 26 centímetros; puño (es la espiga de hierro, con restos de dorado y plateado), 13,6 centímetros; anillo, 2,4 centímetros. El anillo es tubular y su anchura es de 1,8 centímetros. La hoja es bastante estrecha, proporcionalmente, pues sólo mide 2 centímetros. Tiene una curvatura ligera. El arma es de hierroacero.

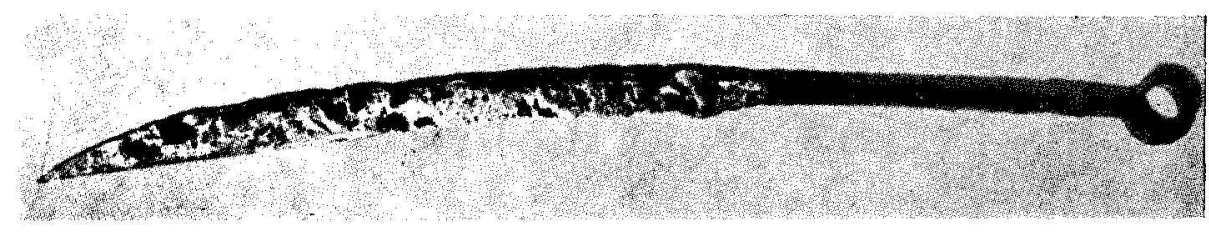

Fig. 1,_Daga búnico-ávara? (Colección del autor. Barcelona.)

Consultadas diversas obras sobre las armas con anillo (no colocado sobre el pomo, como en ciertas espadas y dagas de la baja Edad Media, sino sustituyéndolo), he podido advertir que su área de difusión es mucho más amplia de lo que supuse en principio, tanto en el espacio como en el tiempo. Hay armas de este tipo desde el Japón a Francia, y su cronología se extiende unos dieciocho siglos, con un vacío intermedio de tres a cinco. Dicho de otro modo: empiezan a aparecer armas de pomo de anillo hacia el 1600-1500 a. C. en bronce, y siguen existiendo con discontinuidades (que no he podido llenar, sin duda por lagunas de investigación más que de existencia de tales armas) hasta La Tène III, o sea, el siglo $\mathrm{r}$ a. C. Luego reaparecen en el siglo IV-v d. C., y se las encuentra hasta el viII. Pronto veremos las causas de tales fijaciones temporales.

Respecto al uso del anillo, no cabe establecer más que dos hipótesis: a) se trata de una forma pura, derivada del concepto de puño antropo- 
morfo $($ anillo $=$ esfera $=$ cabeza $)$ o no, o b) el anillo se utilizaba para sujetar el arma a la muñeca o suspenderla del cuello con una cadenita, correa o cordón. Si en el combate saltaba de la mano, era fácil recuperarla y volver a asirla.

Vianello y Berciu citan en los libros que se mencionan en la bibliografía, al final de este artículo, espadas con anillo. El primero publica

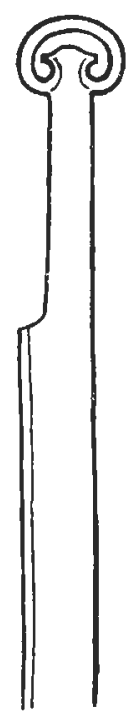

FIG. 2,-Espada. China. Bronce, Siglos $\mathrm{X}-\mathrm{V}$ antes de Cristo.

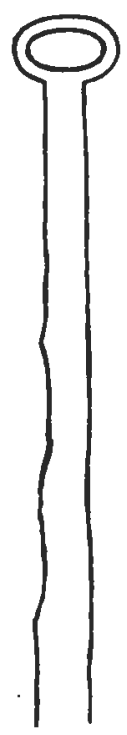

FIg. 3.-Espada. Japón. Bronce. Siglos $\mathrm{X}$ $v$ a. C.

Fig. 4.- Empuñadura de espada. Irán. Bronce. Siglo viri a. C.

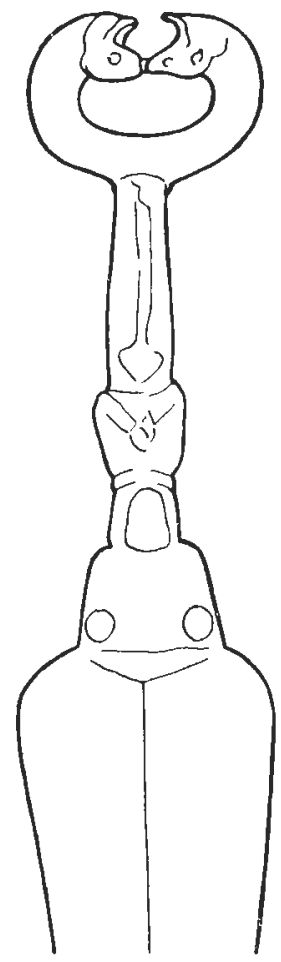

dos, de bronce, una china y otra japonesa (de hoja enteramente recta ambas); el segundo publica una espada con dos antenas que se unen curvilíneamente, dando lugar a un anillo. Es ésta una espada escita, de hierro. La cronología no es muy precisa, pero al parecer las tres piezas son de la misma época, pese a la diferencia de metales: la de Hallstatt (950-450 a. C.). Berciu publica, asimismo, un bello cuchillo con pomo en anillo (el de Spalnaca), que es de la misma época.

6 
De otro lado, Max Loehr, en su importante monografía, asimismo citada al final de nuestro texto, publica una serie de dagas-cuchillo con pomo en anillo que considera de la época Chang (1523-1028) y que serán del final de esa época. Son de bronce y fueron encontradas en Anyan. Publica también una pieza similar proveniente de Ordos, junto al desierto de Gobi, que juzga de época parecida. Todas estas armas son de bronce y su canon es muy distinto del de la daga que describimos al
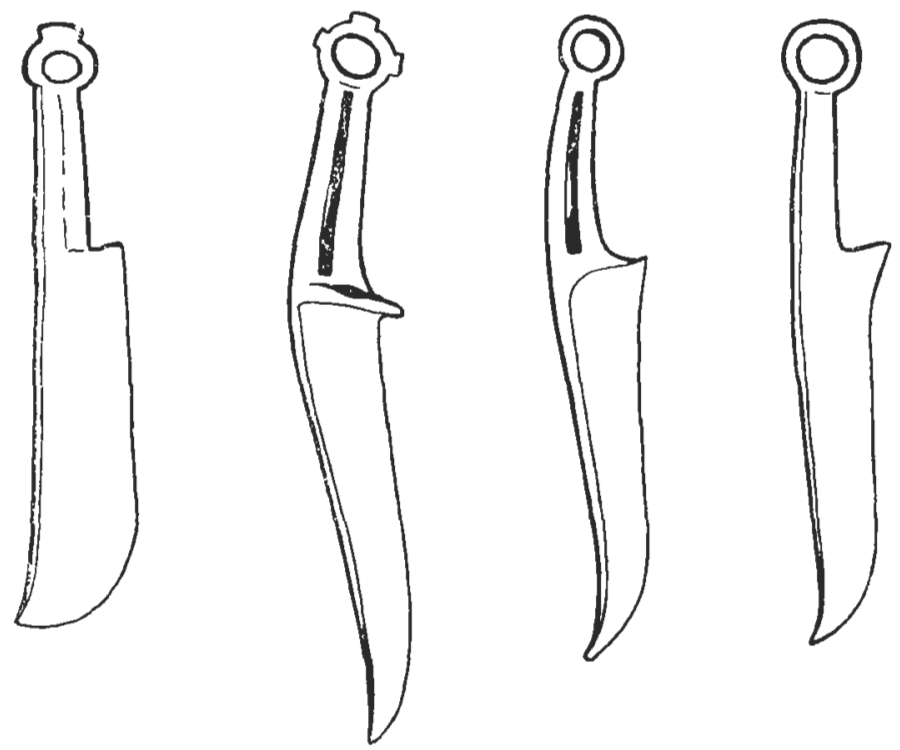

Fig. 5.-Cuchillos-daga. Anyan. Período Chang. Bronce.

inicio (hojas más anchas, puños más sólidos, menos longitud total). Nos encontramos así, en síntesis, con que el arma con pomo de anillo, ya en 1000-500 a. C., abarca un área que va de Japón a Rumania. Esto nos indica claramente - por contextos históricos que pueden considerarse como una verdadera constante en las migraciones y corrientes de influencias - que el origen debe ser chino, de donde irradió al Japón y Siberia meridional —damos un ejemplo en la ilustración- por un lado, y por otro, hacia Occidente, pasando por Asia Central, el Cáucaso y las zonas entre el Don y el Danubio. Allí las cosas empiezan a aclararse. Es sabido que los escitas fueron dueños de Rusia meridional, desde el norte del Irán hasta sus penetraciones en Bulgaria y hacia Centroeuropa. Incluso 
es sabido que los escitas, siguiendo la vía danubiana, mantuvieron largos contactos con los celtas, proseguidos luego por sus sucesores, los sármatas. Los inicios de la cultura escita han de situarse entre los siglos $\mathrm{X}$ y vir a. C., con apogeo en el vi y en el v y un declive que puede llegar al III. Su onda de influencia en Bohemia, Alemania y Francia se mantiene hasta el comienzo de nuestra Era. Es decir, si nos inclinamos por la hipótesis de que todo hallazgo concreto tiene unos «inventores» y luego migra a través del espacio y el tiempo, y no preferimos creet en la «invención simultánea», pues a idénticas necesidades, similares soluciones.

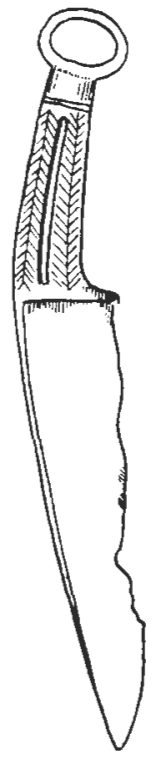

FIG. 6.-Cucbillo-daga. Ordos. Bronce. Ca. 1500 a. C.

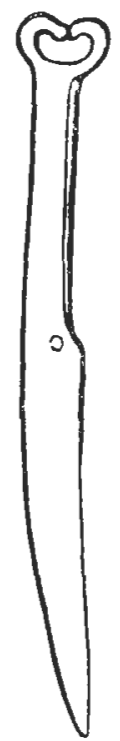

FIG. 7.-Daga sudsiberia. na. Bronce. Siglos $\mathrm{x}$-v a. C.

El caso es que Déchelette publica un grupo bastante nutrido de cuchillos con pomo en anillo, de hierro, como pertenecientes a los períodos La Tène II y III (siglos III a I a. C.), piezas anchas de hoja, de canon corto, muy parecidas entre sí, a pesar de sus diversas procedencias: Sajonia, Hesse, Bohemia, Francia, Hungría, Alta Baviera. Por su forma y sus proporciones, parecen derivar de las dagas-cuchillo chinas de bronce, a pesar de la inmensa distancia espacial y de los siglos que separan unas de otras piezas. Es evidente en todos estos casos europeos que se trata más bien de útiles prácticos, no ornamentales, en los que el refinamiento chino por la forma ya se ha perdido. Incluso carecen de la 
belleza lineal y rítmica de la daga-cuchillo rumana (hallstática) — que es el elemento de transición que conocemos en el espacio y en el tiempoantes mencionada (publicada por Berciu). Más que de armas, como decimos, parece tratarse de cuchillos corrientes, en cuyo caso la finalidad antes citada del anillo no tendría razón de ser. También es verdad que no hay por qué suponer una diferenciación de funciones y que podía tratarse de útiles y armas a un mismo tiempo. Sea como fuere (pues,

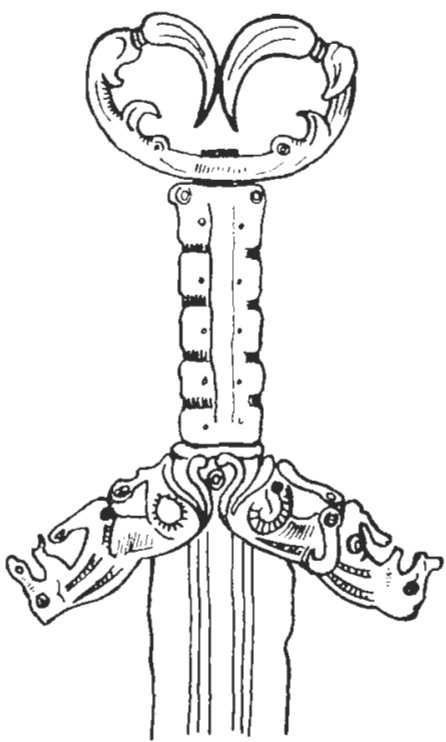

Fig. 8.-Espada escita. Aldoboly, Rumania. Hierro. Ca. 1000-500 a. C.

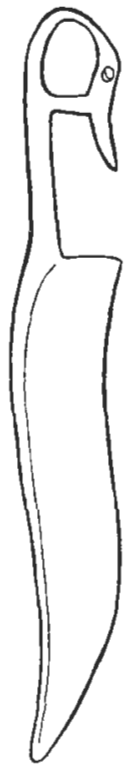

FIG. 9.--Daga escita. Spalnaca, Rumania. Hierro. Ca. 1000-500 antes de Cristo.

honradamente, las hipótesis han de exponerse también en su lado adverso), no se entendería por qué los cuchillos celtas remataban a veces, que no siempre, en anillo y las espadas no. Con todo, Seitz publica una daga La Tène, de hoja estrecha, con aspecto de arma y pomo anular. Es centroeuropea.

Con los cuchillos publicados por Déchelette nos hallamos en los umbrales de nuestra Era. Viene ahora un período de varios siglos en 
que no aparecen armas con pomo en anillo. Pudieron existic y no conservarse. Puede haber alguna conservada y no conocerla el autor de este texto. Pero también pudieron desaparecer mientras duraba la expansión del Imperio romano. En efecto, siendo escasísimas las espadas, dagas, puñales y cuchillos romanos (de la capital o de cualquier provincia del Imperio) conservados, ni uno corresponde a tal tipología, cuyo origen oriental señalamos antes. Es bien sabida la animadversión romana contra todo lo que procediera de Oriente, por lo menos hasta el siglo III, cuan-
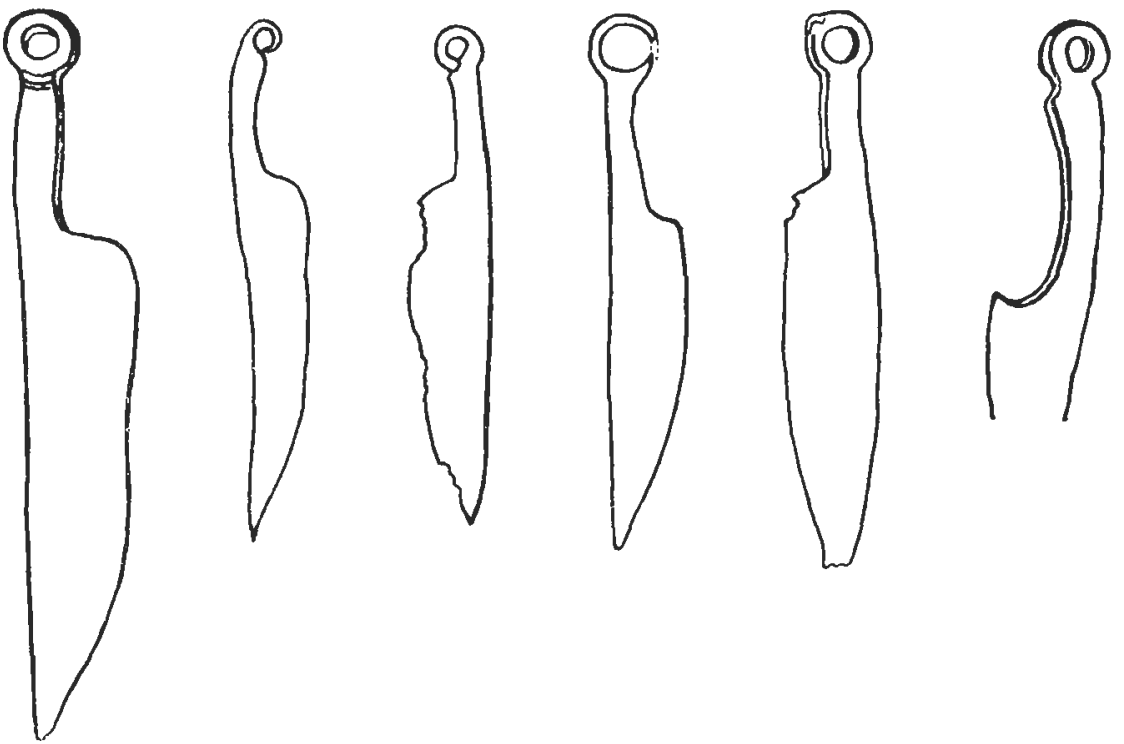

Fig. 10.-Dagas-cuchillo. La Tène. Ceniroeuropa. La última, Francia. Siglos III-I a. C.

do se hizo preciso imitar a los cataphractari partos para no hallarse en inferioridad de condiciones, y Roma cedió a la caballería el papel predominante que en su milicia, desde que hay señales de ella hasta los Severos, desempeñó la infantería pesada: las legiones.

Esto explica el lapso de cuatro o cinco siglos sin armas con pomo en forma anular. Pero la corriente de migraciones orientales hacia Occidente se reanuda. Tras los escitas y sármatas vienen los hunnos, que, en 375 , se hallaban en el Volga, y en 452, en Italia, bajo el mando de Etzel (Atila). Franz Altheim debate el problema de si los hunnos son el pueblo 
nómada que guerreó con China en la época Han (206 a. C.-220 d. C.) y que, derrotados, emprendieron en el siglo I a. C. el éxodo hacia Occidente a través del Asia Central. En tal caso, los hunnos (mongoles, sea como fuere) habrían podido ser portadores - de nuevo- de formas y estructuras extremo-orientales. Los hunnos fueron - tópico- el terror de Europa, pero durante poco tiempo a escala histórica, ya que a finales del siglo vi o principios del VII prácticamente se habían disuelto, bien convirtiéndose en bandas mercenarias o bien siendo asimilados por los pueblos germánicos a los que habían combatido. Hay noticia de armas húnnicas con pomo anular. En pueblos que vivían a caballo, la idea de sujetar las armas al cuerpo por correas, cuerdas o cadenas resulta, más que lógica, imprescindible.

Sucesores de los hunnos fueron los ávaros, pueblo cuyo origen se ignora, habiendo quien los supone nativos de las comarcas al norte del Cáucaso y quien sitúa su habitat primigenio más al este. En todo caso, se trata de un pueblo asiático y seguramente mongol, tal vez de una segunda oleada húnnica parcialmente transformada. Si el auge de los hunnos corresponde a los siglos IV-V, el de los ávaros concierne a las centurias vi-vin. En 517 se hallaban ya en los Balcanes, ocupando Belgrado en 583. Su centro se determinó en Hungría, desde donde hicieron atrevidas incursiones a Baviera y Turingia en 595-596, llegando casi a Francia. Fueran de origen húnnico o no, se sabe que tuvieron contacto con los hunnos y posiblemente acogerían bandas de estos guerreros en sus propios contingentes.

Debo a la doctora Ada Bruhn el conocimiento de que en tumbas húngaras de los siglos VI-VIII se han encontrado espadas con pomo en forma de anillo, derivadas, por tanto, o posiblemente, de las chinas y japonesas por intermedio de los Hiong-hou, el pueblo nómada que Altheim cree posible origen de los hunnos que llegaron a las puertas de Roma. También me da la noticia de que en pinturas rupestres de Qumrân (Asia Central) se hallan represcntadas cspadas y dagas rectas con pomo anular, lo cual nos facilita otro importantísimo hito de referencia en la marcha hacia Occidente de la tipología que nos interesa.

Generalmente, un artículo como el presente debe terminar con afirmaciones, aunque sea a título de hipótesis. Pero el nuestro tiene por fuerza que acabar en interrogación. La daga de ligera curvatura (que publicamos entre las ilustraciones), motivo de este provisional estudio, que, como indica su subtítulo, sólo pretende llamar la atención sobre un tema, desflorándolo apenas y sin poder ahondar y precisar mucho en él, no puede ser clasificado a la luz de los informes que hemos dado. Proveniente sin duda de una de las muchas subastas de antigüedades que 
tienen lugar desde hace mucho en París o Londres, su origen concreto nos es ignorado. ¿A qué época y pueblo perteneció?

$\mathrm{Si}$ es imposible responder a ello, en cambio sí cabe afirmar que se halla dentro de la trayectoria descrita. Por su estado de conservación y la excelente metalurgia, más parece ser de los primeros siglos de la Edad Media (¿húnnica?, ¿ávara?) que anterior. Pero esta idea, que ni al grado de hipótesis puede aspirar, no deja de ser gratuita. Puede afirmarse con mayor probabilidad de certidumbre que su antigüedad está en razón directa con su orientalidad. Si procede de las comarcas centroeuropeas, del Rin al Danubio, se confirmaría la noción de que es un arma de los primeros siglos de la Edad Media. Pero si proviene (por hallarse en el mercado de antigüedades de Occidente) desde hace sesenta

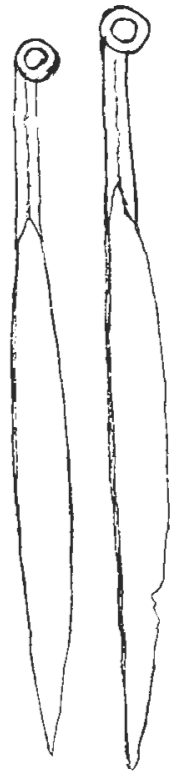

Fig. 11.-Espadas con un corte de una tumba del lémenos. Micenas. Bronce. Ca. 1570-1500 a. C.

años o más del sur de Rusia o del norte del Irán, entonces habría que atribuirle un origen relacionado con las culturas escita y sármata. En todo caso, no tiene relación morfológica marcada ni con las piezas extremo-orientales ni con las descritas y publicadas por Déchelette, parte de las cuales — las otras son de la misma forma y canon- llegan al sur de Alemania y a Francia. No hemos podido consultar la obra de 
W. Ginters Das Scbwert der Skytben und Sarmaten Südrusslands, pero es improbable que aclarara el problema. La originalidad de esta daga radica en varios elementos: su longitud, la estrechez regular de su hoja, que la espiga sea el puño (no podía llevar madera ni hueso encima, puesto que esa ancha y relativamente gruesa espiga ostenta, como dijimos, restos de plateado y dorado) y, finalmente, que el anillo sea tubular, justo de igual ancho que el final de la espiga-puño, la cual, desde ese ancho de 1,8 centímetros, va estrechándose hasta el inicio de la hoja, con 0,5 centímetros a través de su longitud, ya citada, de 13,6 centímetros. No caben más precisiones, ni siquiera más suposiciones. Pero a causa de esta pieza hemos podido ver el avance de un tipo morfológico desde el Extremo Oriente hasta el Occidente de Europa *.

\section{B I B L I O G R A F I A}

Altherm, Franz: Autila et les Huns. París, 1952.

Bruhn, Ada: Comunicación epistolar de 27 de julio de 1970.

Berciu, Dumitru: Romania. Londres, 1967.

Déchelette, Joseph: Manuel d'Archéologie ..., parte III. París, 1914.

ERDÉlyi, Istvan: The ait of the Avars. Corvina, 1966.

Ghirshman, R.: Arte persiana. Milán, 1964.

LoEHr, Max: Chinese bronze age weapons. Michigan, 1956.

SEITz, Heribert: Blankwaffen, tomo I. Brunswick, 1963.

Vianello, Gianni: Armi in Oriente. Milán, 1966.

Varios autores: Arle occidental y del Próximo Oriente. Barcelona, 1970.

* Debo a la doctora Ada Bruhn la noticia sobre la existencia de dagas micénicas de bronce con pomo anular. Las hojas tienen ligera curvatura $y$, por tanto, a diferencia de las espadas rectas conocidas de esa cultura, ofrecen un problema: ¿provicnen esas dagas de culturas exteriores a la micénica?, ¿son obras micénicas influidas por lo oriental? Su fecha es otra incógnita, aunque de todos modos han de situarse entre los siglos Xvis y $\mathrm{x}$ a. C. Y, sin duda, el problema principal que crean, y que deriva de los anteriores, es éste: ¿produjeron los occidentales armas con pomo anular independientemente de la influencia oriental? En tal caso, las piezas de la Edad de Hierro derivarían, a través de los Balcanes y Hungría, de lo micénico, aunque esta posibilidad no invalida la de una influencia oriental o la de varias olas de influencias orientales (escitas, hunnos, ávaros). 